\title{
PERIODISMO
}
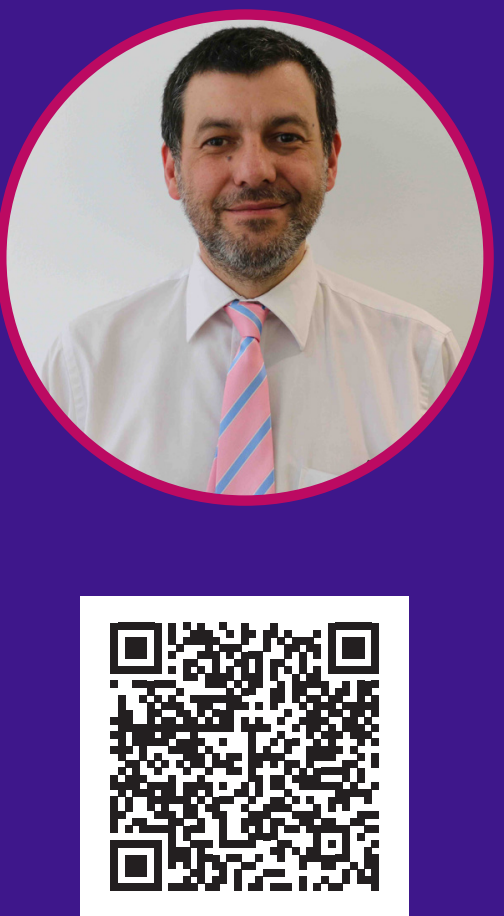

Videopresentación

\section{Un estudio de caso: El Correo Español como medio de información de la colonia asturiana en México (1889-1900)}

\author{
A case study: El Correo Español as a means of information about \\ the Asturian colony in Mexico (1889-1900)
}

\author{
Dr. Îñigo Fernández Fernández \\ Universidad Panamericana, campus México, México \\ infernan@up.edu.mx, ORCID: https://orcid.org/0000-0003-2654-8018
}

Recibido: 13 de agosto de 2021.

Aceptado: 16 de septiembre de 2021.

Publicado: 30 de noviembre de 2021.

\begin{abstract}
Received: August 13th, 2021.
Accepted: September 16th, 2021.

Published: November 30th, 2021.
\end{abstract}

DOI: https://doi.org/10.21555/rpc.vi2.2440

Cómo citar: Fernández Fernández, I. . (2021). Un estudio de caso : El Correo Español como medio de información de la colonia asturiana en México (1889-1900). RPC, (2), 72-85. https://doi.org/10.21555/rpc.vi2.2440

\section{RESUMEN}

El Porfiriato fue una época en la que aumentó la migración de los españoles y, dentro de ella, los asturianos se constituyeron en el grupo mayoritario. En este contexto, El Correo Español, hizo las veces de órgano de información oficial de la colonia hispana asentada en México a finales del siglo XIX e inicios del XX, si bien en el caso particular de los originarios del Principado, no sólo fue un mero medio de comunicación, también ayudó a construir una visión común de su región en ambas orillas del Atlántico. Para tal fin, la publicación contó con una agenda en la que las noticias que privilegió ver- saban sobre el ferrocarril, la minería y los puertos, tres ejes económicos que estaba teniendo pujanza tanto en la comarca europea, al igual que en México, y que además de formar parte de un proceso de modernización, también cumplían con un anhelo ilustrado que acabar con el aislamiento que había caracterizado a Asturias gracias a su peculiar geografía.

Palabras-clave: El Correo Español, México, Asturias, prensa, historia. 


\section{A B STRACT}

The Porfiriato was a time when Spanish migration increased and, within it, Asturians became the majority group. In this context, El Correo Español served as the official information organ of the Hispanic colony settled in Mexico at the end of the 19th century and the beginning of the 20th, although in the particular case of those who came from the Principality, it was not only a mere media, also helped build a common vision for their region on both sides of the Atlantic. To this end, the publication had an agenda in which the news it privileged dealt with the railroad, mining and ports, three economic axes that were gaining momentum both in the European region, as well as in Mexico, and also of being part of a modernization process, they also fulfilled an enlightened desire to end the isolation that had characterized Asturias thanks to its peculiar geography.

Keywords: El Correo Español, Mexico, Asturias, press, history.

\section{INTRODUCCIÓN}

$\mathrm{E}$ n castellano la llaman "nostalgia", en italiano "nostalgia", en francés "nostalgie", en alemán "nostalgie", en portugués "saudade" y en asturiano "morriña". Para los asturianos la "morriña" es algo más que una simple palabra, es una manera de nombrar a la sensación de profunda tristeza que les arrebata cuando están lejos de su tierra y de sus seres amados.

Un sentimiento como éste sólo puede echar raíces en quien se ve obligado a migrar a por periodos prolongados pero, siempre, con la idea de volver al hogar en algún momento. En el caso particular de los asturianos, el siglo XIX fueron un tiempo de inmigración y de grandes esfuerzos para cumplir el sueño de "hacer la América"; es decir, de viajar al Nuevo Mundo, en especial a Cuba, Argentina, México y Uruguay (Fernández-Peña Bernaldo de Quirós, 2014, p. 4), ${ }^{1}$ con la idea de trabajar y amasar grandes fortunas para regresar a su tierra cargados de dinero y prestigio.

En el último tercio del siglo XIX, México fue un país atractivo para la migración española, en general, y

1 Los destinos de la inmigración están ordenados del mayor al menor receptor de inmigrantes asturianos. asturiana, en particular. El gobierno del general Porfirio Díaz (1877-1911) fue el escenario de grandes cambios económicos y sociales que pusieron de manifiesto que la modernización del país - producto en gran medida de un orden autoritario- era una realidad. Parte de este fenómeno fue consecuencia de la llegada de los recursos económicos provenientes de Estados Unidos y de Europa, que, según Bailey, se invirtieron "primordialmente en la minería, el petróleo y la agricultura, así como préstamos para la expansión de los ferrocarriles y el telégrafo" (1985, p. 45), es decir, en áreas estratégicas para el desarrollo económico de la nación. Las jugosas ganancias que muchos extranjeros obtuvieron en el corto y mediano plazos hicieron las veces de un efecto replicador que incentivó el asentamiento de un mayor número de asturianos en el país.

El crecimiento de la comunidad asturiana en México favoreció la construcción de espacios de sociabilidad que fomentaban la convivencia y la ayuda entre sus miembros, preservaban sus costumbres y tradiciones al tiempo que les permitían mantener los vínculos con su región. Se trataba, pues, de una experiencia que ayudaba a mitigar la nostalgia al tiempo que alimen- 
taba el sentimiento de pertenencia regional y nacional que, entonces, no estaban distanciados.

Un recurso que ayudó a alcanzar lo anterior fue el de los periódicos. Aunque los asturianos no fundaron uno propio, como el resto de los emigrados de la Península, al menos contaron con El Correo Español, publicación importante para entender la historia del periodismo en México que hizo las veces de órgano principal de la comunidad hispana en México (Lepidus, 19271928, p. 451), que para el año 1900 era la más grande entre las extranjeras con un total de 16,278 componentes, de los cuales una tercera parte provenía de Asturias (INEGI y González, 1977, p. 396).

Es a partir del supuesto anterior que el presente texto, una investigación hemerográfica de carácter exploratorio, parte de la perspectiva de que este diario no sólo era un periódico que proveía de noticias sobre Asturias a los inmigrados en México; también fue un medio de comunicación que aspiraba a construir una visión común de la región entre los asturianos en ambas orillas del Atlántico. ${ }^{2}$ En su ensayo "A Cultural Approach to Communication", James Carey definió, y defendió, la visión cultural de la comunicación en el entendido de que las noticias son una realidad histórica, "una forma de cultura inventada por una clase particular, en un punto particular de la historia [...] (1989, p. 20)", cuya razón de ser no está encaminada a extender un mensaje por el espacio, sino a "la construcción y mantenimiento de un mundo cultural ordenado [y] significativo" (198, p. 18) que se articula a través de la representación de creencias comunes. Dentro de esta óptica, queda claro que El Correo Español bien puede ser visto como un caso en el que una publicación periódica se inserta en un proceso simbólico de producción, mantenimiento y transformación de una "realidad" común, a la par que distante, en el seno de una comunidad de emigrados.

En este periódico se publicaron notas de diversa índole sobre Asturias, pero si éstas aspiraban a

2 Entendemos que este proceso de construcción podía tener un carácter consciente en el conjunto de los españoles en México, pero definitivamente inconsciente en el caso de la asturiana. Dicho de otro modo, la publicación aspiraba a fomentar el orgullo nacional, el regional era responsabilidad de cada comunidad. proyectar y construir entre los asturianos asentados en México una visión de su región, entonces, cabe preguntarnos icon qué tipo de temas el periódico favoreció la construcción y mantenimiento de este mundo compartido entre México y España?

A raíz de la cantidad y variedad de noticias que El Correo seleccionó y publicó sobre el tema, optamos por centrar nuestro análisis en aquellas relacionadas con las tres a las que el periódico le dio mayor peso: el ferrocarril, la minería y los puertos, en el entendido de que componían un circuito que, a su vez, formaba parte de otro más complejo y de mayores dimensiones. ${ }^{3}$ De igual modo, y en virtud de la longevidad del diario -26 años-, delimitamos nuestro marco temporal entre 1889 y 1900, es decir, desde su fundación hasta el cambio de siglo.

\section{ALGUNAS CONSIDERACIONES SOBRE EL CORREO ESPAÑOL Y LOS ASTURIANOS EMIGRADOS A MÉXICO DURANTE EL PORFIRIATO}

El 9 de noviembre de 1889 el vasco Fernando Luis Juliet de Elizalde sacó a la luz El Correo Español con la aspiración de promover la "defensa de los intereses de los españoles" en estas tierras. En el programa del periódico explicó que dicha misión estaba ceñida a tres causas fundamentales: España, la colonia española en México y México. Sobre la primera, proclamaba la defensa de la monarquía y de la religión católica y el reconocimiento de los progresos que el país estaba viviendo en su interior; en tanto que de la segunda reconocía su laboriosidad y su habilidad para "despertar las poderosas energías del comercio, de la industria y de las artes". Por último, admiraba de México su carácter hospitalario, las virtudes populares y el paso firme que llevaba hacia un mejor porvenir, derivado de la "mano bienhechora que gradualmente lo conduce por tan buen camino" (Elizalde, 1889, pp. 10-11), y que no era otra más que la del general Porfirio Díaz.

3 Los otros componentes de la modernización económica y material de Asturias en este tiempo lo conformaron la construcción de caminos, el incremento de la actividad comercial con el resto de España y con Europa, la introducción del alumbrado eléctrico y la telefonía, y el crecimiento industrial. 
En el periódico imperaba una visión armónica de España y de los españoles asentados en México, que era producto de la creencia en un proyecto de nación común basado en los progresos material y moral y de la convicción de que aquello era "precisa consecuencia de las incontrastables leyes de la evolución natural” (Elizalde, 1889, p. 10); es decir, de un proceso consustancial del que España no se podía sustraerse. Y es justo por ello que otra de las razones de ser del periódico era la de dar cuenta del progreso que estaba teniendo lugar en la propia España, de ahí que Juliet de Elizalde escribiera que "no en menos escala emplearemos nuestras aptitudes para hacer la propaganda a favor de los progresos científicos, económicos, fabriles y comerciales que con tanta rapidez va llevando España al feliz terreno de los acontecimientos realizados" (Elizalde, 1889, p. 10). De este modo, sostenía de manera implícita que España y México eran naciones que no sólo estaban hermanadas por un pasado, un idioma y una cultura comunes, también por un progreso material que mejoraba su presente y les ofrecía un futuro prometedor.

Sobre la relación entre Asturias y El Correo Español, la pregunta que nos debemos hacer es: ¿de qué fuentes abrevaba para publicar las noticias sobre la región durante esta época? Queda claro que la respuesta se encuentra en los periódicos españoles a los que tenían acceso desde México el editor y su equipo. Sin embargo, habría que diferenciar entre las que fueron fuentes directas y los que hicieron las veces de indirectas.

En las primeras comprendemos a los periódicos asturianos de los que escogieron libremente las notas, a saber: El Auseva (de Cangas de Onís), El Comercio (de Gijón y en circulación actualmente), El Correo de Asturias, (de Oviedo y que estaba destinado para los asturianos en Cuba), El Carbayón (de Oviedo), El Diario de Avilés (Avilés), El Diario de Occidente (de Luarca), El Eco (Cangas de Tineo), El Musel (de Gijón), El Nalón (¿de Luarca?), El Oriente (de Llanes), La Opinión (de Villaviciosa) y La Voz de Luarca (Luarca). Todas ellas son publicaciones que destacan, particularmente, por sus contenidos detallados y por sus vívidas crónicas.

Por las indirectas entendemos las que se publicaban en España -probablemente en periódicos de Madrid y Barcelona, por ser las ciudades más importan- tes-, y que se hacían de las noticias de sus pares asturianos para reproducirlas, algunas veces, bajo epígrafes como los de "tomado de un periódico de Asturias...", "la prensa de la región comenta..." y, por lo general, a través de artículos de redacción breve y directa. Aunque no contamos con sus nombres, asumimos su existencia no sólo por los enunciados anteriores, también por el poco detalle que sus editores pusieron en más de una ocasión al escribir algunos nombres -como los de "el Muzel" (en lugar de "el Musel") o de Guijón (por "Gijón)- y cuya reiteración en el cuerpo de las noticias nos hacen suponer que su procedencia no era asturiana y que los fallos provenían de la fuente española y no del diario mexicano.

En cuanto al proceso migratorio asturiano en el México decimonónico, este alcanzó su culmen durante el régimen del general Porfirio Díaz. Prueba de ello es que en el periodo de 1880 a 1911, este grupo componía el $35.6 \%$ de la colonia española, seguido por el de los santanderinos con apenas el 15.1\% (González, 1977, p. 396). ${ }^{4}$

¿Por qué aumentó el flujo de emigrantes asturianos a México? En la segunda mitad del siglo XIX, Asturias se caracterizaba por ser una región de minifundios arrendados (Rueda, 2006, p. 120) ${ }^{5}$ en la que, a pesar del progreso industrial y minero, en el año 1900 el 78.9\% de los hombres trabajaban en el campo (Mikelarena y Azpilicueta, 1996, p. 97). Precisamente este talante rural ha originado dos discursos historiográficos encontrados sobre el tema y que para fines del presente escrito denominamos como "tradicional" y "revisionista". El primero atribuye la salida mayoritaria de los asturianos a una crisis económica que se reflejaba en la pobreza en la que vivía el campesinado, el aumento de la actividad industrial en la región y la alta densidad poblacional en el campo. Por el contrario, el segundo advierte que los argumentos anteriores deben ser matizados en virtud de la existencia de dos razones de peso: el deseo creciente del campesinado por radicar

4 El autor comenta que realizó el cálculo con datos "de las estadísticas oficiales de emigrados españoles y con los procedentes del Archivo de la Beneficencia española en Méjico" consultados por él.

5 Rueda puntualiza que sólo el 6\% de los agricultores asturianos eran propietarios. 
en América para dedicarse al comercio -sin importar que en la mayoría de los casos ocuparan empleos terciarios- (Rodríguez, 1992, p. 137), y la migración entendida como una costumbre arraigada entre los jóvenes con ambiciones económicas, que ansiaban que algún familiar afincado en América los reclamara (Rodríguez, 1992, pp. 112-127).

Este último factor es importante pues, si vemos el perfil del emigrado asturiano, encontraremos que en la mayoría de los casos se trataba de varones jóvenes y solteros con algún pariente en el Nuevo Mundo. Muchos salían para trabajar y hacerse de riqueza, pero otros, y no pocos, lo hacían huyendo del servicio militar, lo que les "iba a suponer de todas formas, años de destierro" (Pozuelo, 2009, p. 264).

Los asturianos en México tenían la idea de que la experiencia sería temporal, de que una vez que enriquecidos 0 , bien, que el servicio militar hubiera prescrito, volverían a casa para continuar con sus vidas. A estos retornados se les llamaba "indianos" y, como bien señala Fernández-Peña, aunque el término siempre se ha asociado con la riqueza, ello no es correcto dado que "no se tiene en cuenta que sólo una minoría, una elite, alcanzó el triunfo [...]. Una mayoría silente fracasó en el empeño, y cayó en el olvido" (2014, p. 91). ${ }^{6}$

La mayor parte de los asturianos en México provenían de los concejos de Cabrales, Llanes, PeñameIlera, Rivadedeva y Ribadesella, si bien Oviedo, la capital del Principado, proveía cerca de un $21,8 \%$ de los emigrados, quienes salían por los puertos de Gijón y Llanes (Rodríguez 1992, pp. 98-101 y Rosas Salas, 2011, p. 17), los más importantes de Asturias. Todos llegaban a Veracruz, ciudad en la que algunos se quedaban en tanto que otros partían hacia rumbos tan diversos como la capital del país, Guadalajara, Puebla o el norte de la República.

Su presencia se hizo notar rápidamente en la Ciudad de México gracias a la constitución de espacios

6 Esta idea errada es producto de las grandes construcciones que los emigrados retornados levantaron por toda Asturias, pero principalmente en la región occidental de la provincia. Se trata de verdaderos palacetes, todos con el distintivo de tener una gran palmera sembrada en el jardín como recuerdo de su estadía en América, que dieron origen a un estilo arquitectónico en la región denominado como "indiano". de sociabilidad que, aunque estaban concebidos para fortalecer los vínculos entre los emigrados y paliar los efectos de la nostalgia, también tuvieron un carácter punto incluyente. A manera de ejemplo, mencionaremos la celebración de Virgen de Covadonga cada 8 de septiembre, que, a pesar de ser una festividad asturiana, a finales de la década de los años noventa del siglo XIX se convirtió en una celebración en la que participaba toda la colonia española. ${ }^{7}$

Los asturianos se integraron a actividades económicas relacionadas con la agricultura especializada, la banca, el comercio, la ganadería y la industria. Unos pocos llegaron a ser prósperos propietarios y se convirtieron en mecenas de sus pueblos al llevar a ellos servicios como el agua y la luz, y al apoyar obras de beneficencia como escuelas, hospitales y asilos. Sin embargo, la mayoría, particularmente en las ciudades, terminaron siendo asalariados no cualificados (Cerutti, 1999, pp. 145-146 y Moreno Lázaro, 2007, p. 117) de cuyas vidas no nos quedan testimonios.

\section{EL CORREO ESPAÑOL Y LA CONSTRUCCIÓN DE UN MUNDO ASTURIANO TRANSATLÁNTICO}

El Correo fue muy generoso tanto en la cantidad como en los contenidos que publicó sobre lo que acontecía en el Principado de Asturias. Había un optimismo sobre el presente y el devenir de la región que apenas se vio opacado por los sucesos de la guerra hispano-estadounidense de 1898.

De todas las temáticas que publicó en sus páginas, hubo tres de mayor recurrencia e importancia: el ferrocarril, la minería y los puertos. Es de suponer que los editores del periódico mexicano tomaran esta agenda de sus colegas asturianos. Esta suposición es plausible en virtud de que tales aspectos económicos y comunicacionales habían tenido un carácter nodal en tiempos de la Ilustración española, gracias al pensamiento de Gaspar Melchor de Jovellanos (1744-1811), y siguieron vigentes en el siglo XIX.

7 El 8 de septiembre se celebra el aniversario de la Batalla de Covadonga, que tuvo lugar en el año 722, y que en la historiografía tradicional española marcó el inicio de la Reconquista y fue la semilla de la que nació la España contemporánea. 
Hombre de letras y funcionario, Jovellanos siempre se mostró interesado por reformar las costumbres e instituciones de su tiempo y hacer de España una nación más próspera y moderna. Impulsó la educación, con la fundación de escuelas e institutos, al tiempo que abogó por una reforma económica de corte liberal que acabara con las aduanas interiores, privatizara los montes comunales, eliminara los impuestos al cereal e incentivara la inversión de la Corona en obras públicas para mejorar la vida de los súbditos y comunicar a todo el reino. En gran medida, su idea de progreso estuvo presente en el proyecto modernizador de la Asturias decimonónica y la construcción de ese mundo de significados que compartieron los asturianos en las dos orillas del Atlántico.

En lo que al Principado se refiere, sabía que su geografía le había marcado históricamente, pues las escarpadas montañas que componen la cordillera cantábrica la aislaban de Castilla y de su ciudad más cercana: León. Si bien a lo largo de los siglos esta condición fue tomada como indeseable pero natural, Jovellanos trabajó para revertirla. Defendió le necesidad de desarrollar las infraestructuras marítima y terrestre de Asturias para vincularla con el resto del país, y, en particular, con la meseta castellana y aseguraba que era fundamental construir un camino que comunicara con las provincias meridionales de la Península para incentivar el comercio y la industria asturianos y ayudar a la prosperidad de Ciudad Rodrigo, León, Ponferrada, Salamanca y Zamora (Ocampo Valdés, 2000-2001, p 72).

También fue un gran promotor de la minería pues la consideraba como pieza clave en el bienestar de los asturianos y en el progreso de su tierra. En 1781 manifestó que: "[... ] el suelo de Asturias abunda mucho de carbón fósil o de piedra. ¡Cuántas utilidades se sacarían del beneficio de estas minas, si la sociedad descubriese el modo de hacer servir el carbón de piedra para las ferrerías, fraguas y otras oficinas donde se trabajan los metales!" (Jovellanos, 1781, s. p.). Visto así, el problema de la región no radicaba en su ausencia de riqueza, más bien en la subutilización de su mineral más preciado: el carbón.

Si para Jovellanos los caminos eran la puerta de salida de los productos asturianos a la cornisa can- tábrica y la meseta castellana, y la minería una de sus fuentes comerciales más importantes, los puertos, en especial el de su natal Gijón, devinieron en arietes que romperían de una vez por todas el aislamiento de Asturias con el resto de España y de Europa.

En su Informe sobre la ley agraria, de 1795, el pensador asturiano señalaba genéricamente que había provincias marítimas al tiempo que industriosas que carecían de buenos puertos y no gozaban de los beneficios del comercio marítimo. Aunque no mencionaba nombres, en realidad hacía alusión a su ciudad natal y apuntaba que "es, pues, necesario, si aspiramos a él [al comercio activo], mejorar nuestros puertos marítimos y multiplicarlos, y facilitando la exportación de nuestros preciosos frutos dar el último impulso a la agricultura nacional" (Jovellanos, 1846, pp. 266-267). En este sentido, su propuesta no tendía a fomentar el comercio marítimo de manera aislada, más bien, aspiraba a vincularlo con las comunicaciones interiores del Principado, es decir, con un sistema de caminos, canales y ríos que tuvieran como destino los puertos.

Estas premisas del pensamiento de Jovellanos sobrevivieron a su muerte y permearon a una élite económica y política asturiana que se asumió como su heredera y como la responsable de ejecutarlas y cuyos alcances se pueden percibir a finales del siglo XIX en las páginas de EI Correo Español.

Desde sus orígenes, en los años treinta del siglo XIX, el ferrocarril en Asturias tuvo una impronta industrial y minera en el que los servicios de tipo general (Ferrocarril del Norte, Ferrocarril de Langreo y Ferrocarriles Económicos de Asturias) se combinaban, especialmente, a partir de los años ochenta del siglo XIX, con los tendidos ferroviarios de servicio particular. Estos últimos eran propiedad de las compañías mineras y siderúrgicas y respondían a la necesidad de vincular los centros de extracción y producción con los de exportación que, por lo general, eran los puertos. Tal necesidad conllevó la inversión de grandes capitales pues la geografía accidentada de las cuencas de los ríos Caudal y Nalón, las regiones mineras por excelencia, obligaba a la construcción de una infraestructura de apoyo -como puentes- que vinculara estas líneas particulares con las generales. 
El Correo fue muy generoso en la publicación de noticias al respecto; sin embargo, puso un mayor énfasis en la construcción de las líneas de Oviedo a Infiesto y de Infiesto a Santander.

El ramal que conectaba la capital de la provincia con Infiesto inició su construcción en 1888. Las notas en las que se mencionaban los avances en la construcción del ferrocarril -tendidos, almacenes, rampas...- se entremezclaban con otras que poseían un carácter propagandista que elogiaba las bondades de la modernización. En noviembre de 1889, y a poco de haber iniciado el proyecto, podemos leer en el periódico: "Esta gran obra iniciada por los amantes de los progresos locales de Asturias [...] ha sido eficazmente secundada por los capitalistas de la Provincia [...]", y, más adelante, se añade: "si los capitalistas de allende y de este lado del Atlántico que proceden de cuna y hogar asturianos quisieran, como lo han querido en el ferrocarril de Oviedo a Infiesto, impulsar los intereses locales, Asturias sería la primera provincia del Reino por su industria, sus medios de comunicación y su desarrollo de riqueza" (El Correo Español, noviembre 16 de 1889, p. 35). Un año después, el diario volvió a hacer otro llamamiento, éste dirigido a México, en el que apuntaban que "grande bajo todos conceptos sería para esa digna provincia de nuestra patria que sus hijos millonarios que viven en México tomarán acciones de ese ferrocarril, con lo cual impulsarán las obras que deberán inaugurarse [...]" (El Correo Español, julio 16 de 1890, p. 2).

Este tipo de invitaciones, aunque no frecuentes, eran un guiño hacia los asturianos emigrados, un recordatorio de que ,a pesar de la distancia, su región seguía contando con ellos. No obstante lo anterior, en este caso fueron los capitales locales, encabezados por el banquero Pedro Masaveu Masaveu, los que se encargaron de sacar el proyecto adelante con la creación de la compañía Ferrocarriles Económicos de Asturias. ${ }^{8}$

Aunque El Correo no lo mencione, el ferrocarril Oviedo-Infiesto se inauguró el 13 de noviembre de

8 Las otras compañías ferrocarrileras existentes en Asturias eran: La Compañía del Ferrocarril de Langreo (1847), el Ferrocarril del Norte (1855), la Compañía de los Ferrocarriles Económicos de Asturias (1887), la Sociedad General de Ferrocarriles Vasco-Asturiana (1899) y el Ferrocarril de Carreño (1900).
1891. A pesar de esta omisión, el periódico sí dio cuenta del éxito inicial de la línea, y transcribió notas en las que se señalaba que vecinos de las parroquias y concejos por los que éste atravesaba solicitaban la construcción de rampas y apeaderos para utilizar sus servicios. De igual modo, en 1897, daba cuenta de que el personal técnico de la compañía Ferrocarriles Económicos de Asturias había estado en Ribadesella con el fin de estudiar las variaciones necesarias para construir el tramo entre Infiesto y esta villa, fundamental para unir las capitales asturiana y cántabra (El Correo Español, julio 16 de 1897, s. p.).

Si bien las noticias sobre el movimiento de las mercancías y personas y los ingresos que reportaba la línea en su tramo inicial no debían revestir mayor interés para los lectores, en su conjunto era una prueba fehaciente del ferrocarril. Mientras que en agosto movilizó a 15,557 viajeros y transportó 1,220 toneladas, generando un ingreso de 33,118 pesetas, al siguiente mes los datos comprendían 17,828 viajeros, 1,660,828 toneladas y 38,036 pesetas (El Correo Español, octubre 6 de 1892, s. p. y El Correo español, noviembre 2 de 1892, s. p.); es decir, un aumento del $14.5 \%, 31 \%$ y $14 \%$, respectivamente, cifras que incentivaron la construcción de pequeños ramales que aumentaran el flujo de personas y productos y, claro está, de la mencionada extensión a Ribadesella.

Sobre lo anterior, el periódico informaba que, a pocos meses de la inauguración de la vía Oviedo-Infiesto, en Ribadesella se había formado una sociedad peticionaria que poseía un capital que alcanzaba las 250,000 pesetas y que anhelaba la ampliación de la línea hasta su villa en el plazo de un año (El Correo Español, septiembre 26 de 1891, p. 21). Pese a que la meta no se cumplió en tiempo, al menos fue ejemplo del interés que este medo de transporte despertó en la zona.

El motivo de este atraso se debió a que, aunque el monto anterior era importante, a la postre no fue suficiente pues el proyecto se modificó para que abarcara la ruta Ribadesella-San Vicente de la Barquera-Cabezón de la Sal (las dos últimas en Cantabria), lo que implicó un desembolso de 16,651,000 pesetas. Para justificar este coste tan alto, Manuel Huidobro, Director Gerente de la Compañía del Ferrocarril del Cantábrico y 
encargado de la conexión interprovincial, explicaba que se conseguiría "en el mayor ensanche de relaciones económicas de las provincias del Norte entre sí y con Francia, consecuencia necesaria de la unión que con el ferrocarril en proyecto quedará realizada entre líneas muy separadas" (El Correo Español, diciembre 15 de 1899, s. p.). Pero, ¿por qué el Director Gerente de la Compañía del Ferrocarril del Cantábrico se refería a un tema que, al menos en principio, era predominantemente asturiano? Al respecto, Peris señala que "[Los Ferrocarriles] Económicos de Asturias y el Ferrocarril del Cantábrico negociaron en secreto la unión de ambas líneas [...]. Las conversaciones se llevaron a cabo en Santander desde 1899, llegando a un acuerdo autorizando los Consejos de Administración, un proyecto de convenio para la construcción y explotación del sector entre Infiesto y Cabezón de la Sal (s. f.)". Como es de suponer, El Correo jamás dio cuenta esta transacción.

En 1900, el periódico difundió una noticia en la que se refería al éxito de este proyecto al señalar que ya era un hecho la unión de los ferrocarriles de Santander a Cabezón de la Sal y de Oviedo a Ribadesella en un plazo no mayor a cinco años (el tramo Oviedo-Santander sería inaugurado el 20 de julio de 1905); es decir, ya estaba todo listo para dar vida a la línea que conectara a las dos capitales provinciales, lo que implicaría la unión entre San Vicente de la Barquera (Cantabria) y Arriondas (Asturias) a través de un tendido que estaba en construcción (vía Llanes) y que se culminaría a inicios del siglo XX. Sobre las ventajas de este plan, el periódico consignaba que Asturias estaría comunicada con la cornisa cantábrica y se hallaría un poco más cerca del País Vasco, el mercado más importante que tenía su carbón en toda España.

En el siglo XIX, y parte del XX, la minería fue la actividad distintiva de la economía asturiana y uno de sus motores más sólidos. En los años veinte del siglo XIX, la Corona impulsó la actividad con la promulgación de la Ley de Minas de 1825 que, entre otros beneficios, dio cauce a las primeras solicitudes de explotación mineras (Rodríguez Terente, 2006, p. 23). Fue tal su éxito inicial que, en las décadas siguientes, particulares y compañías extranjeras -como Duverger, Chaviteau et Compagnie y la Asturian Coal \& Iron Company- solici- taron al gobierno regional diversas concesiones en las que a la explotación del carbón sumaron otras, como la del antimonio, cinc, cobalto, cobre, hierro, manganeso, oro y plomo (Rodríguez Terente, 2006, p. 41). El aumento en la extracción de minerales favoreció la reapertura de la fábrica de armas de Trubia y la construcción de caminos, primero, y de tendidos ferroviarios, después, así como la apertura de minas con carácter temporal (Anes, 1983, p. 15).

Para los dueños de las minas, al igual que para la economía de la región, la cuestión del transporte era primordial pues la construcción temprana del ferrocarril en Langreo (cuenca del río Nalón) había permitido que esta zona se convirtiera en el centro siderúrgico de España en los años sesenta del siglo XIX, en tanto que la aparición tardía de este medio en la zona de Mieres (cuenca del río Caudal) retrasó el desarrollo de sus explotaciones mineras y siderúrgicas hasta los años ochenta.

Al respecto, El Correo siempre destacó la importancia de la minería para Asturias con la publicación de noticias que daban fe de los logros la actividad estaba alcanzando en la provincia. Muchas de estas notas contenían datos duros que se presentaban como signos de un mejor futuro para el Principado y sus habitantes. Destaca la información sobre los registros de mina que el gobierno Civil de Asturias otorgó, todos solicitados por individuos la gran mayoría de ellos asturianos. Aunque éstos se concentraban en los años 1891 y 1899, ofrecían un panorama comparativo interesante pues, mientras que en la primera fecha el periódico refirió al registro de 7 minas, 1 de hierro y 6 de carbón, en la segunda las cifras alcanzaron las 31 minas, 18 de carbón, 6 de hierro, 1 de azufre, 1 de blenda, 1 de calamina, 1 de cobre, 1 de plomo y 1 de zinc, lo que representa un crecimiento del $440 \%$. En cuanto a la extensión de los terrenos reclamados, en el primer año el promedio fue de 28 hectáreas, en tanto que en el segundo alcanzó las 146, lo que implica un aumento del 521\%. (El Correo Español, septiembre 2 de 1891, p. 1, El Correo Español, septiembre 8 de 1891, p. 1, El Correo Español, noviembre 12 de 1891, p. 1 y El Correo Español, febrero 24 de 1899, p. 1) Aunque es difícil suponer que alguno de los lectores hubiera realizado este ejercicio, tampoco se puede ne- 
gar que las cifras correspondientes al año 1899 sorprendieron a más de uno.

Las cifras del carbón eran muy alentadoras, si bien su extracción no estuvo exenta de problemas provocados por la competencia del procedente de Inglaterra, cuyo mineral era más barato y de mejor calidad. El periódico testimonia que las sociedades mineras supieron afrontar el reto al organizar, en 1890, las sociedades mineras organizaran la "Liga de los Interese Hulleros de Asturias" y la "Liga General de Intereses Hulleros de España” como instancias que presionara al gobierno para que protegiera a la minería en la Península. Así, el 31 de diciembre de 1891, las autoridades aceptaron duplicar la protección al carbón asturiano, que pasaba de las 1,25 pesetas por tonelada a las 2,5 y, con ello, lograron que las minas de carbón asturianas aumentaran su producción en el corto plazo.

Como muestra de ello, El Correo publicó un artículo en 1894 en el que anunciaba que España consumía al año 3.000,000 millones de toneladas de carbón, de las cuales $1.600,000$ eran importadas y $1.400,000$ de producción nacional. De las últimas, Asturias aportaban 770,000 toneladas, es decir, el 55\% (El Correo Español, febrero 22 de 1894, p. 1). No obstante lo anterior, estos números quedaron pronto rebasados pues, en 1898, el sector minero asturiano había doblado su producción al alcanzar las 1.542,974 toneladas (El Correo Español, julio 21 de 1899, p. 3).

El periódico destacó que este logro se debía fundamentalmente a las sociedades mineras en Asturias, empresas que eran nombradas y su producción desglosada de la siguiente manera (El Correo Español, julio 21 de 1899, p. 3):

\begin{tabular}{lc|} 
& TONELADAS \\
\hline $\begin{array}{l}\text { Sociedad Hullera Española (Aller) } \\
\text { (capital cántabro) }\end{array}$ & 277,000 \\
$\begin{array}{l}\text { Sociedad Fábrica de Mieres (capi- } \\
\text { tal francés) }\end{array}$ & 255,000 \\
\hline $\begin{array}{l}\text { Unión Hullera y Metalúrgica de As- } \\
\text { turias (capital asturiano) }\end{array}$ & 242,000 \\
$\begin{array}{l}\text { Sociedad Hullera de Turón (capital } \\
\text { vasco) }\end{array}$ & $155,000^{1}$ \\
\hline
\end{tabular}

1 Estas compañías, como varias de las que se mencionan más adelante, construyeron sus propios tendidos ferroviarios para poder transportar el carbón a las ciudades, fábricas y puertos asturianos.
Estas cuatro empresas eran las más fuertes y sostenían la mayor parte de la producción, con el 60\% del total. El resto de la misma recaía en las siguientes sociedades, que se consolidaron en el sistema de la extracción del carbón entre 1895 y 1899: Herrero Hermanos (capital asturiano), Coto del Musel (capital vasco), Carbones Asturianos (capital vasco) y Real Compañía Asturiana (capital asturiano) (Anes, 1983, p. 28). La presencia de tres compañías mineras propiedad de vascos, entre las ocho que más carbón extraían en Asturias, es un claro indicador de la importancia que tenía el carbón asturiano para la industria de esta región española. Ello no es de extrañar pues, como lo señalamos páginas atrás, el mercado principal del carbón asturiano se haIlaba en el País Vasco, en particular en el puerto Bilbao, donde era utilizado en las fábricas y siderurgias que tanto impulso dieron a la economía de esa provincia de finales del siglo XIX (El Correo Español, septiembre 29 de 1891, p. 1).

En lo que se refiere a los puertos, a las labores del de Gijón, habría que sumar las del de Avilés, de tal modo que, como lo comenta Rueda Hernánz, entre 1857 y 1920 ambas ciudades transportaban el 14\% del volumen total del comercio marítimo español, el mayor del país, situándose por encima de Barcelona, que representaba entonces el 10\% (Rueda Hernánz, 2006, pp. 90-91).

Sobre Gijón, su éxito se dio a mediados del siglo XIX y conjuntó a la minera y al ferrocarril, de tal modo que el puerto se convirtió en el receptor del carbón de las cuencas mineras de los ríos Caudal y Nalón, lo que a su vez redundó en su ampliación con la construcción del dique de Santa Catalina, el muellín y la dársena del Fomento (Delgado Viñas, 2010 y Vallina, 2014). A pesar de estas obras, el tamaño pequeño del puerto y su poco calado se convirtieron en obstáculos para su desarrollo.

La búsqueda de la solución a este problema fue motivo de debates entre las clases acomodadas de Gijón en los años setenta del siglo XIX. Quienes tenían propiedades en la ciudad eran conocidos como "apagadoristas" (porque se referían a la ampliación del muelle como Puerto Apagado) y abogaban por mejorar las condiciones del puerto y así garantizar el valor de sus pro- 
piedades urbanas. El otro bando era el de los "muselistas", grupo compuesto por lo que defendía la propuesta de construir un nuevo puerto comercial y de refugio en El Musel, lugar que se encontraba a una distancia corta de la villa y que colindaba con sus fincas rústicas Quirós Linares, 19080. P 188 y Vallina, 2014).

Tras dos décadas de discusiones, que beneficiaron a otros puertos emergentes (como el de San Esteban de Pravia), hubo un consenso a favor de la ampliación del de Gijón y la construcción de El Musel. Así, el 30 de octubre de 1891, y por real decreto, la Corona aprobó la construcción del nuevo puerto. Sin embargo, lo anterior no evitó que el proyecto se enfrentara a serios contratiempos. La dificultad para encontrar los materiales de construcción adecuados, los temporales propios del mar Cantábrico, las insuficiencias técnicas, la descoordinación entre contratistas y los conflictos con los obreros, fueron factores que retrasaron su inauguración hasta 1907.

En lo que concierne a los puertos de Gijón y El Musel, El Correo les dio un tratamiento distinto. Las noticias del primero giraban en torno a las cifras sobre el movimiento de barcos y mercancías y, en menor grado, a algunos cambios infraestructurales. Del segundo, y en virtud de que se hallaba aún en obras en el periodo estudiado, abundaron las notas sobre el inicio de su construcción y el potencial que tenía.

Los asturianos avecindados en México se enteraron de que, entre 1889 y 1890, la Junta de Obras del Puerto de Gijón acordó hacer algunos cambios en el puerto para subsanar las limitaciones logísticas que le aquejaban. Sus miembros determinaron la ampliación del rompeolas de Liquerique para proteger las embarcaciones de los embates del mar cantábrico; el derribo del muro de la calle del comercio para agilizar la llegada de los trenes provenientes de Langreo; la colocación de rieles para facilitar el movimiento de las grúas y, por último, la construcción de un embarcadero de atraque de 200 metros de largo por 40 de ancho (El Correo Español, noviembre 9 de 1899, p. 2 y El Correo Español, enero 5 de 1890, p. 3). El causante de estos cambios era el carbón pues el aumento en su extracción, así como la disminución en su tiempo de traslado y el incremento de su consumo en España habían saturado las zonas de almacenamiento y descarga de los muelles gijoneses.
Los números en El Correo dan cuenta de un crecimiento sostenido, aunque con variaciones, en la salida de carbones por Gijón, de tal modo que, entre 1892 y 1897, el mayor monto correspondió al mes de mayo de 1895, con 20,002.06 toneladas, y el menor a junio de 1892, con 16,345,02 toneladas (El Correo Español, agosto 13 de 1892, s. p. y El Correo Español, julio 16 de 1897 , s. p.). Estimamos que el promedio para este periodo rondaba entre las $17,000.00$ y las $18,000.00$ toneladas mensuales.

Por las noticias que el periódico publicó sobre el movimiento de navegación en Gijón, queda claro que se trataba de un puerto netamente de interés nacional. Más del $90 \%$ de los barcos que atracaban en él, y de sus pasajeros, eran de origen español y tan sólo unos pocos provenían de otros países, básicamente de Alemania e Inglaterra.

¿Cómo podía interpretar un asturiano en México este panorama? Era una cuestión de enfoque. Algunos podían ver en ello un motivo de entusiasmo pues implicaba un paso más en contra del asilamiento tradicional; para otros, en cambio, la escasa llegada de navíos del extranjero podía ser un motivo de desánimo puesto que Gijón era uno de los puertos más importantes de la cornisa cantábrica. En tanto que habría otros que opinarían que ello era un argumento sólido a favor de El Musel.

Las discusiones sobre la conveniencia de uno u otro puerto en realidad se remitían al año 1850 cuando iniciaron las obras de El Musel, mismas que se suspendieron en 1856 y, después de varias disputas e intentos por reiniciarlas, fue hasta 1891 cuando la Corona autorizó su construcción. Este primer momento del proyecto generó gran regocijo en el periódico, que lejos de querer fomentar las disputas en aras de promover una imagen del progreso de la región entre sus lectores, publicó una nota en la que compartía la buena nueva de la siguiente manera:

El Correo Español se asocia con verdadero júbilo a las manifestaciones de entusiasmo con que el noble y valiente pueblo asturiano celebró la fausta noticia [...] ella viene a favorecer los cuantiosos intereses que encierra aquella 
bella y pintoresca región de nuestra España, y a hacer que la hermosa Villa de Gijón, cuna del inmortal Jovellanos, alcance la preponderancia comercial en el Cantábrico, dadas las ventajosas condiciones que dicho puerto ha de ofrecer a la marina mercante de todos los países y, sobre todo, a la manufactura extranjera que obtiene los productos de la rica e inagotable cuenca huIlera y metalúrgica asturiana (El Correo Español, agosto 26 de 1891, p. 1).

Tal como sucedió con el ferrocarril y la minería, la construcción de El Musel representaba la promesa de un mejor futuro para la región por diversos motivos. A los manifestados en la cita anterior, se suman el de ser el "puerto donde está el porvenir de la industria asturiana” (El Corres Español, octubre 14 de 1891, p. 1), la condición necesaria para aumentar la extracción de minerales y metales de las minas asturianas, la base para multiplicar la riqueza regional, la posibilidad de dar "cuerpo a uno de los más grandes pensamientos de Jovellanos" y de realizar "el sueño dorado de los hijos de Asturias" (El Correo Español, septiembre 3 de 1892, s. p.), al tiempo que el medio para cambiar rápidamente el rostro de Asturias y su gente.

Las plumas más optimistas traspasaron los límites regionales para referirse a los beneficios que la propia España obtendría de esta obra. Como El Musel era el primer puerto español cuyo meridiano dejaba por el este la costa francesa, los barcos que partieran de ahí rumbo a Falmouth y Plimouth podrían hacerlo sin necesidad de pasar por la costa de Bretaña y sin hacer correcciones de rumbo, con lo cual llegarían a su destino en menos de 24 horas, un récord para entonces. Ahora bien, en virtud de que esta era la ruta más cercana entre España e Inglaterra y de que Asturias ya estaba conectada por tren con León -lo que permitía el establecimiento de una ruta férrea comercial norte-sur que pasara por Salamanca, Mérida, Huelva, Cádiz y Algeciras-, El Musel era visto como la llave maestra que abriría las puertas de los mercados de Alemania, Bélgica, Dinamarca, Holanda, Inglaterra, Suecia, Noruega y Rusia a los productos de toda España (El Correo Español, septiembre 3 de 1892 , s. p.).

\section{CONCLUSIONES}

El Correo no sólo informaba a los asturianos emigrados. También ayudó difundir entre ellos, y a pesar de la distancia, una serie de creencias comunes generadas en el Principado en torno a tres ejes temáticos -el ferrocarril, la minería y los puertos- que representaban dos ideas claramente establecidas. Por un lado, la del progreso material que tenía, entre otras repercusiones, el fin del aislamiento tradicional de la región con el resto de España. Por el otro, y estrechamente vinculado, el cumplimiento de un proyecto concebido décadas atrás por Gaspar Melchor de Jovellanos.

A partir de lo anterior, cabe preguntarnos sobre las ideas del ferrocarril, de la minería y de los puertos que los asturianos afincados en México pudieron hacerse. Expresado de otra manera, ¿cómo recibieron el mensaje emitido por el periódico y las fuentes consultadas por éste? Una manera de empezar es identificar los términos con los que cada uno de estos tópicos fue asociado en las páginas del diario, a saber:

1. Ferrocarril: "alegría”, "beneficio", "comercio", "conquista”, "energía”, "prosperidad”, "progreso", "rédito", "resultados", "satisfacción", "triunfo" y "riqueza".

2. Minería: "animosidad", "aumento", "comercio", "consumo", "desarrollo", "importancia", "inteligencia”, "intensidad", "mejor", "positivo” y "riqueza".

3. Puertos: "comercio", "desarrollo", "entusiasmo", "exportación”, "felicidad”, "importancia”, "producción”, "regocijo”, "riqueza” y “trabajo”.

Todas estas palabras son positivas y apelan a ámbitos diversos pero que están bien diferenciados: los sentimientos, las finanzas y la laboriosidad; elementos que, sin lugar a dudas, ayudaron a gestar una idea positiva de la pequeña patria tanto en España como en México. De igual modo, destacamos que sólo hay dos términos que se repiten en los tres campos: "comercio" y "riqueza", lo que es un primer punto de encuentro 
en esta construcción a ambas orillas del Atlántico, pues una parte considerable de los emigrados asturianos en México se dedicó a la primera para generar la segunda.

En este mismo orden de ideas, el progreso al que se refería el periódico era una suerte de ejercicio de transferencia por el que los asturianos en los dos continentes se ponían en una misma sintonía. Asturias pasaba por una bonanza económica y material que prometía un futuro mejor y México también compartía el mismo proceso y signo. Así como el ferrocarril, la minería y los puertos crecían a pasos agigantados en el Principado, el fenómeno se estaba replicando a una velocidad similar en tierras mexicanas. Los capitales extranjeros se sumaban a la generación de riqueza y desarrollo infraestructural en la región española, al tiempo que hacían lo propio en el país americano. En ambas naciones surgió un grupo de personas que dejaron a un lado la vida de rentista, considerada entonces como ociosa y estéril, por una productiva en la que invertían sus capitales en proyectos productivos. Por último, mientras que en España no eran pocos los asturianos que trabajan arduamente en la producción de la riqueza, en México existía un colectivo de emigrados que laboraba afanosamente para producir y acumular capital en beneficio propio y del país en el que residían.

Desde esta perspectiva, tiene sentido que la prensa de Asturias, probablemente conocedora del eco que tenía en México, lanzara invitaciones para que los asturianos emigrados sumaran a sus inversiones tradicionales -escuelas, hospitales...- obras de mayor alcance, como el ferrocarril, bajo la premisa implícita de que la emigración era un mero accidente, jamás un elemento de exclusión, que no impedía la suma de esfuerzos para alcanzar el progreso su tierra natal.

Consideramos que un aspecto fundamental en el que El Correo colaboró activamente en el proceso al que nos referimos fue el de la idealización de Asturias entre los emigrados. Con ello no nos referimos al burdo ejercicio de presentar los aspectos positivos y ocultar los negativos, pues esta práctica no tuvo lugar en el diario en la medida en que repetidamente dio cuenta de las huelgas de los obreros y mineros, de los altos costes de transportación ferroviaria y de la pobre calidad del carbón asturiano. No. Esta idealización se fundamenta- ba en la anteposición de lo bueno a lo malo con la finalidad de generar un sentimiento de orgullo entre los lectores.

En el contexto de una región tradicionalmente aislada en materia geográfica y de una productividad económica limitada, la constitución de compañías ferrocarrileras y mineras con capitales asturianos, la construcción regular y ordenada de tendidos ferroviarios, el crecimiento en el número de petición de registros de mina, los datos formidables sobre la extracción y venta del carbón, la modernización de los puertos existentes, la apertura de nuevos para responder a las demandas comerciales de la provincia y los alcances potenciales que cada uno de estos logros despertaban, devinieron en razones suficientes para que los asturianos en España y México se sintieran orgullosos y esperanzados. No podía ser menos, si consideramos que era la primera vez en la historia de Asturias que empezaban a concretarse las ideas que Jovellanos había concebido tiempo atrás. I 


\section{REFERENCIAS}

» Anes, R. (1983). La industria asturiana en la segunda mitad del siglo XIX: de la industrialización a la expansión hullera, Revista de Historia Económica-Journal of Iberian and Latin American Economic History, I(2),13-29.

»Anónimo (septiembre 8 de 1891). Correo de Asturias, El Correo Español, 1.

» Anónimo (1889, 16 de noviembre). Provincias de España, El Correo Español, 35

» Anónimo (1890, 16 de julio). Sección editorial, El Correo Español, 2.

»Anónimo (1897, 16 de julio) Noticias de España, El Correo Español, s. p.

» Anónimo (agosto 13 de 1892). Notas del Principado de Asturias, El Correo Español, s. p.

» Anónimo (agosto 26 de 1891). El Puerto de Musel, El Correo Español, México", 1.

» Anónimo (diciembre 15 de 1899). Noticias de España, El Correo Español, s. p.

»Anónimo (enero 5 de 1890). Provincias de España, El Correo Español, 3.

»Anónimo (febrero 22 de 1894). Los carbones españoles, El Correo Español, 1.

» Anónimo (febrero 24 de 1899). Notas españolas, El Correo Español, 1.

»Anónimo (julio 16 de 1897). Noticias de España, El Correo Español, s.p.

» Anónimo (julio 21 de 1899) Notas españolas, El Correo Español, 3.

»Anónimo (julio 21 de 1899). Notas españolas”, El Correo Español, 3.

»Anónimo (noviembre 12 de 1891). Correo de Asturias, El Correo Español, 1.

» Anónimo (noviembre 2 de 1892). Noticias del Principado de Asturias, El Correo Español, s. p.

»Anónimo (noviembre 9 de 1889). Provincias de España, El Correo Español, 2

»Anónimo (octubre 14 de 1891). Correo de Asturias, El Correo Español, México", 1.

»Anónimo (octubre 6 de 1892). Noticias del Principado de Asturias, El Correo Español, s. p.

»Anónimo (septiembre 2 de 1891). Correo de Asturias, El Correo Español, 1

»Anónimo (septiembre 26 de 1891), El Correo de Asturias, El Correo Español, 1.

»Anónimo (septiembre 29 de 1891). Noticias de Asturias, El Correo Español, 1

» Anónimo (septiembre 3 de 1892). Inauguración del Puerto de 'El Muzel' [sic], El Correo Español, s. p.

» Bailey, N. (1989.) La inversión extranjera en México. En Riordan R. (coomp.), México y Estados Unidos. El manejo de la relación (pp. 45-62), Siglo XXI Editores.

» Carey, J. (1989). A Cultural Approach to Communication, Communication as Culture, 13-36.
» Cerutti, M. (1999). Empresarios españoles en el Norte de México (1850-1912), Revista de historia económica, XVII, pp. 143-190.

» Delgado Viñas, C (2010). Entre el puerto y la estación. La influencia de las infraestructuras de transporte en la morfología de las ciudades portuarias españolas (1848-1936), Scripta Nova. Revista electrónica de Geografía y Ciencias Sociales, XIV(30 , s. p pttp:// www.ub.edu/geocrit/sn/sn-330.htm.

» Elizalde, J. F. L. de (1889, 9 de noviembre) Sección editorial. Nuestros propósitos. Programa de "El Correo Español", El Correo Español, 9-12.

» Elizalde, J. F. L. de (1889, 9 de noviembre) Sección editorial. Nuestros propósitos. Programa de "El Correo Español", El Correo Español, 9-12.

» Fernández-Peña Bernaldo de Quirós, M. M. (2013). La oligarquía indiana. Asturias-Cuba. Opinión pública y propaganda (18981899) [Tesis doctoral. Universidad Complutense de Madrid. Facultad de Ciencias de la Información, Madrid].

" García Quirós, P. (s. f.). Minería y ferrocarril minero en Asturias a finales del siglo XIX. Docutren. http://www.docutren.com/HistoriaFerroviaria/Gijon2003/pdf/p14.pdf.

» González Loscertales, V. (1977). Política del Porfiriato, emigración peninsular y emigración canaria a México: análisis comparativo de la emigración peninsular y canaria en Morales Padrón, F. I coloquio de Historia Canario-Americano, (pp. 384-403), , Cabildo de Gran Canaria, 1977, http://mdc.ulpgc.es/cdm/ref/collection/coloquios/id/155

》Grupo de Trabajos Ferroviarios (s. f.). Ferrocarril de Langreo. http://www.grupotrabajosferroviarios.es/langreo.html.

» Gutiérrez Domínguez, M. del M. (2016). La Batalla de Covadonga en México. Imaginarios en torno a la Reconquista (1889-1900) Estudios de Historia Moderna y Contemporánea de México, 51, 37-52

» INEGI (S. F.) Censo general de la República Mexicana, http://www. beta.inegi.org.mx/proyectos/ccpv/1900/.

» Jovellanos, G. M. de. (1781). "Informe sobre la ley agraria", en Obras de Don Gaspar Melchor de Jovellanos. Nueva edición, Tomo II (pp. 33-287), Establecimiento Tipográfico de D. F. de P. Mellado.

" Jovellanos, G. M. de. (1781). Discurso económico sobre los medios de promover la felicidad de Asturias dirigido a su Real Sociedad por Don Gaspar Melchor de Jovellanos, Madrid, S. E.. http://www.cervantesvirtual.com/portales/gaspar melchor de_jovellanos/obra-visor/discurso-economico-sobre-los-medios-de-promover-la-felicidad-de-asturias-dirigido-a-su-real-sociedad-por-don-gaspar-melchor-de-jovellanos/html/ f07fc8c9-c125-467f-b28b-4a2f14125958_28.html\#I_0

» Lepidus, H. (1927-1928). Historia del periodismo mexicano en Romero de Terreros, M. (traductor). Anales del Museo Nacional de Arqueología, Historia y Etnografía, Imprenta del Museo Nacional de Arqueología, Historia y Etnografía, cuarta época, 380-471.

» Llordén Miñambres, M y R. Rodríguez. (1998) Álvarez. Patrimonio documental y bibliográfico asturiano, Universidad de Oviedo. 
» Mikelarena F, y M. P. Azpilicueta (1996). Algunas consideraciones acerca de la evolución de la población rural en España en el siglo XIX, Noticiario de Historia Agraria, 6(12). 12, 1996, 91-118.

» Moreno Lázaro, J. (2007). La otra España. Empresas y empresarios españoles en la Ciudad de México durante la Revolución, América Latina en la Historia Económica. Revista de Investigación, 27, 109-156.

» Ocampo Suárez-Valdés, J. (2000-2001). Caminos y economía (II) Jovellanos y la carretera de Castilla (un informe y tres cartas inéditas), Cuadernos de estudios del siglo XVIII, Oviedo, 10-11, 2000-2001, 75-92.

» Peris Torner, J. (s. f.). Ferrocarriles Económicos de Asturias (Oviedo, Infiesto , Arrióndas y Llanes). En Ferrocarriles de España, España. http://www.spanishrailway.com/2012/08/16/ferrocarriles-economicos-de-asturias-ii/.

» Pozuelo, A. Y. (2009). "Las relaciones masónicas entre Asturias e Hispanoamérica en los siglos XIX y XX. Estado de la cuestión, Revista de Estudios Históricos de la Masonería Latinoamericana y Caribeña, San José, Costa Rica, 1(1), 262-281.

» Quirós Linares, F. (1980). El puerto de Gijón, Ería: Revista cuatrimestral de geografía, 1, 179-221.

» Rodríguez Terente, L. M., C. Luque Cabal y M. Gutiérrez-Claverol (2006). Los registros mineros para sustancias metálicas en Asturias, Trabajos de Geología, 26, 19-55.

» Rodríguez, J. J. (1992). Asturias y América, Editorial Mapfre.

» Rosas Salas, S. F. (2011). Inmigración, inversión e industria en Puebla. La trayectoria empresarial de los hermanos Díaz Rubín, 1878-1914, Tzintzun. Revista de Estudios Históricos, 53, 11-46.

» Rueda Hernánz, G. (2006). España 1700-1900, Ediciones Istmo. 2006.

» Rueda, G. (2006). España 1790-1900, Ediciones Istmo.

» Vallina, M (2014). Relación puerto-ciudad, Regeneración urbanística y territorial integrada: Gijón, 7-20. 